African Journal of Biomedical Research, Vol. 11 (2008); 311 - 321

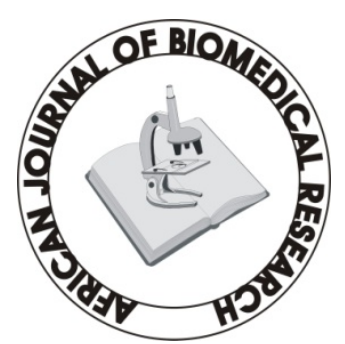

Full-text available at http://www.ajbrui.com http://www.bioline.br/md http://www.ajol.com

Received:

December 2007

Accepted (Revised):

April 2008

Published

September 2008
Full Length Research Article

\section{Pharmacological and toxicity studies of the crude extracts and fractions of Hedranthera barteri leaf in rats and mice}

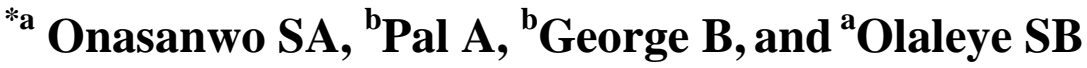 \\ ${ }^{a}$ Department of Physiology, \\ College of Medicine, University of Ibadan, Ibadan, Nigeria. \\ ${ }^{b}$ GRB Division, Central Institute of Medicinal and Aromatic Plants, \\ Lucknow, UP, India.
}

\begin{abstract}
This study assessed the anti-nociceptive and anti-inflammatory potency of the hydro-ethanol extract and fractions from Hedranthera barteri leaf. Column chromatography of the crude extracts, practical acute toxicity testing and fixed dose procedures were carried out. Effects of the extracts on nociception were assessed by tail immersion test in rats, formalin-induced paw licking in rats and acetic acid-induced writhing in mice. The effect of the extracts on inflammation was assessed by carrageenan-induced paw oedema in rats. The hydro-ethanol extracts of Hedranthera barteri reduced nociception and inflammation in a dose-dependent manner. SNG 1, SNG 2 and SNG 3 were separated from the ethanol fractions. The spectra of the compound suggest the presence of a fatty compound, $\beta$-sitosterol, as an anti-nociceptive and antiinflammatory compound that may be present in the leaf of the plant.
\end{abstract}

(Afr. J. Biomed. Res. 11: 311 - 321)

Key Words: Hedranthera barteri, nociception, inflammation, toxicity, $\beta$-sitosterol

*Address for Correspondence: E-mail: sa.onasanwo@mail.ui.edu.ng

Mobile: +2348055264769 


\section{INTRODUCTION}

Hedranthera barteri, HB (family, Apocynaceae) is a Nigerian endemic plant used in folk medicine for the treatment of painful inflammatory disorders. The shape of the free bi-carpelate fruits evokes the bawdy Ijaw name: "goat testicles" and Yoruba name: (oko aja) meaning "dog's penis", Dalziel (1937). The Yoruba people use the exudates from the leaf for treatment of painful tumor (Ainslie, 1937), malarial and hiccups (Chukwujekwu et al, 2005). Screening of some Nigerian medicinal plants reported $\mathrm{HB}$ to have antibacterial and antimalarial activities (Chukwujekwu et al, 2005). The leaf has been demonstrated to have analgesic and anti-inflammatory properties, and contain some secondary metabolites like flavonoids, alkaloids, saponins (Onasanwo and Elegbe, 2006). Several studies have shown that other classes of naturally occurring substances including xanthones, tannins and saponins, possess antinociceptive properties (Aydin et al, 1998; Pinheiro et al, 1998 and El Sayah et al, 1999). This research work was carried out to study the toxicity, identify the fractions and probable compounds that may be responsible for its pharmacological activities.

\section{MATERIALS AND METHODS}

\section{Experimental animals:}

Sprague Dawley albino rats (150-220g) and Swiss mice (29 -35g) were used for this study. The breeding was done at the central animal house of the Central Institute of Medicinal and Aromatic Plants (CIMAP), Lucknow, India. The animals were fed with rat and mouse cubes and water ad libitum. The animals were kept in a photo periodcontrolled environment (12 hours light/dark cycle).

\section{Plant material:}

Hedranthera barteri (HB) leaves were purchased from the Herbarium Department, Forest Research Institute of Nigeria (FRIN), Ibadan, Nigeria. The plant was identified and authenticated and the voucher specimen (FHI-106485) was deposited in the same department.

Crude Extract Preparation: The HB leaves were dried under shade and reduced to powdery form $500 \mathrm{~g}$ of the powered sample was exhaustively extracted with ethanol through soxhlet extractor. The solvents were removed at $52^{0} \mathrm{C}$ under reduced pressure in a rotavapor. The solid samples of the extract were stored in the refrigerator and fresh extract was prepared each day of the experiment as suspensions with $2.5 \%$ tween 80 /saline for the physiological and pharmacological experiments.

\section{Acute toxicity:}

Fixed dose procedure (Guideline 420) of Organization for Economic Cooperation and Development (OECD) (Botham, 2004) was carried out using thirty two mice divided into four groups to identify any change in weight; basic haematological parameters (using MS-4 counter); serum glutamic-oxaloacetic transaminase (SGOT) and serum glutamic-pyruvic transaminase (SGPT) by kinetic method; creatinine (picrate method) and glucose (glucose oxidase method) levels (using RA-50 analyzer). Group 1 (control) received normal saline while other 3 groups received $200 \mathrm{mg} / \mathrm{kg}$ (effective dose) of the AEHB, $\mathrm{AQ} / \mathrm{EEHB}$ and EEHB. The animals in each group were treated with the extract for 28 days before the analysis.

\section{Antimicrobial screening of the crude extracts of HB:}

The plant extracts were screened for in-vitro antibacterial activity against 10 different strains of bacteria. Disc diffusion assay for antimicrobial (antibacterial) screening was carried out using Bauer et al (1996) disc agar method with slight modifications. Petri dishes containing $20 \mathrm{ml}$ of SDA were spread plated with $100 \mu \mathrm{L}$ of $0.5 \%$ McFarland standard inoculum. Sterile $3 \mathrm{~mm}$ diameter disc (whatman) impregnated with $20 \mu \mathrm{l}$ of extract were placed on the surface of the media and incubated at $37^{\circ} \mathrm{C}$ for $24-48$ hours. Strains tested are Staphylococcus aureus, Escherechia coli, Enterococcus faecalis, Mycobacterium smegmatis, Klebsiella pneumoniae, Yersinia 
enterocolitica, Bacillus subtilis, Enterobacter aerogenes, Salmonella typhi and Streptococcus mutans.

\section{Analgesic and anti-inflammatory studies}

Tail immersion method in rats: This method was carried out by immersing about $5 \mathrm{~cm}$ of the tail tip of rat into warm water, maintained at $50 \pm 1^{0} \mathrm{C}$ and time taken for the withdrawal of the tail were taken at $0,30,60$ and 90 minutes after the administration of the extract or drug, p.o. (UmaDevi et al, 1999).

Formalin-induced paw licking in mice: $20 \mu \mathrm{L}$ of $2.5 \%$ formalin was injected into the plantar surface of the left hind-paw (Murray et al, 1988; Hunskar and Hole, 1997). The test was carried out in a transparent plastic chamber $(30 \times 30 \times 30) \mathrm{cm}$ with a mirror placed at the base of the chamber to allow an unobstructed view of the rats. Each animal was allowed to explore the chamber 5minutes before receiving an injection of formalin. The time mice spent licking the injected paws was measured as an index of pain or nociception. The test animal was given the extract, p.o. before the administration of formalin. The 1st phase (initial nociceptive response) was 5 minutes after formalin injection (0-5min). The 2nd phase (second nociceptive response) was between 15 to 30 minutes, post injection.

\section{Acetic acid-induced abdominal writhing in mice:}

The mice were injected, i.p. with $0.2 \mathrm{ml}$ of $3 \%$ acetic acid solution, one hour after extract treatment. This induced the characteristic writhing (Siegmund et al, 1957; Koster et al, 1959). The number of writhing and contraction of the abdominal muscle together with stretching of the hind limbs was observed between 5 and 15 minutes. The data were computed according to the following formula:

Percentage Inhibition $=$

Writhing (control) -writhing (test) X $100 \%$

Writhing test (control)

Carrageenan-induced paw oedema: An injection of $0.1 \mathrm{ml} \mathrm{1 \%}$ carrageenan was delivered into the right hind paw of each rat under the subplantar aponeurosis which produced pedal inflammation in male Wistar rats according to Winter et al (1962). The animals were treated with the extract, p.o. an hour before carrageenan injection. Measurement of the paw volume was carried out by plethysmometrically.

The inhibiting activity was calculated according to the formula:

Percentage $(\%)$ inhibition $=$

$$
\frac{\left[\mathrm{C}_{t}-\mathrm{C}_{\underline{o}}\right]_{\text {control }}-\left[\mathrm{C}_{\underline{t}}-\mathrm{C}_{\underline{o}}\right]_{\text {test }}}{\left[\mathrm{C}_{\mathrm{t}}-\mathrm{C}_{\mathrm{o}}\right]_{\text {control }}}
$$

where $\left[C_{t}-C_{o}\right]=$ change in paw size

\section{Chromatographic methods}

Column Chromatography: Ethanol, hexane, chloroform, acetone, ethyl acetate and methanol were used in the column chromatography. $73.6 \mathrm{~g}$ of the extract was dissolved in methanol and impregnated on Silica gel at ratio 1:10 before introducing onto the Column (a glass support $28 \mathrm{x}$ $2.5 \mathrm{~cm}$ ). Elution was started with pure hexane; thereafter the eluent polarity was increased to $1 \%$, $3 \%, 6 \%, 11 \%, 15 \%, 20 \%, 30 \%, 50 \%, 70 \%$ and $100 \%$ of acetone in hexane. Fractions were collected and distilled off to obtain named residues.

Preparative thin-layer chromatography (PTLC): Slurry of Kieselgel Silica gel (60pf. $254+366$ ) was made and poured evenly into the rectangular well of the hopper located on the end plate (placed over the spreader). This was then drawn steadily over the glass plate surface $(20 \times 20 \mathrm{~cm})$. The coated plate was activated at $120^{\circ} \mathrm{C}$ in the oven for about 2 hours. The loading of the sample was done by using a capillary tube and applying successive spots touching each other following a line drawn across one end of the plate (about $2 \mathrm{~cm}$ from the edge). The extract was chromatographed on the plates. The appropriate solvent system was used to develop the plates. The bands were observed under ultra-violet light (with different $\mathrm{R}_{\mathrm{f}}$ values). The components was removed from the plates by inscribing a line around the bands, then the desired areas was scraped-off into a micro-column previously packed with a glass wool. The layers 
was eluted with appropriate eluents and then concentrated at room temperature or filtered after dissolution in the solvent if there are no impurities.

COX-2 Inhibitor screening assay (in-vitro): This was carried out by prostaglandin screening enzyme immunoassay method using COX (ovine) inhibitor screening assay (catalog no: 560101).

\section{Instrumentation}

Spectral analysis: NMR (1H and 13C), FAB MS and IR were used for spectral analysis. Nuclear magnetic resonance (NMR) spectras were recorded on a Bruker DRX-300 AVANCE spectrometer $(300 \mathrm{MHz})$ in $\mathrm{CDCl}_{3}$. Chemical shifts were recorded in p.p.m. $(\delta)$ relative to $\left(\mathrm{CH}_{3}\right)_{4} \mathrm{Si}$ (TMS; $80: 0 \mathrm{ppm}$ ) whereas the residual solvent peak was used as an internal reference for ${ }^{13} \mathrm{C}$ NMR. The abbreviations s, d, dd, t, q, m, brs are used for singlet, doublet, double-doublet, triplet, quartet, multiplet, broad-singlet signals.

The Fast Atom Bombarding Mass Spectra (FABMS) were recorded on the JEOL SX 102/DA-600 Mass Spectrometer/Data System using Argon/Xenon $(6 \mathrm{kV}, 10 \mathrm{~mA})$ as the FAB gas. The accelerating voltage was $10 \mathrm{kV}$ and the spectra were recorded at room temperature. MNitrobenzyl alcohol (NBA) was used as the matrix unless specified otherwise. The matrix peaks may appear at $\mathrm{m} / \mathrm{z} 136,137,154,289,307$ in the absence of any metal ions. If the metal ions such as $\mathrm{Na}^{+}$are present these peaks may be shifted accordingly.

Infrared spectra (IR) were recorded on a PerkinElmer 567 spectrophotometer.

\section{Statistical analysis}

The results of the experiment were expressed as mean \pm S.E.M. The statistical significance of difference was estimated by Student's $t$-test for unpaired comparison. Probability (P) less than 0.05 was considered significant.

\section{RESULTS}

Acute toxicity study: The HB extracts caused no mortality up to $3.2 \mathrm{~g} / \mathrm{kg}$.

Weight changes induced by $\mathrm{HB}$ extracts in mice: There was no significant change in weight measured in the test groups of $200 \mathrm{mg} / \mathrm{kg}$ of the leaf extracts of $H B$ when compared with the control group.

\section{SGOT, SGPT, creatinine and glucose levels evaluation}

The results in table 1 show that there were no significant changes in the SGOT, SGPT, creatinine and glucose levels when the values of the crude extracts were compared with the control.

\section{Table 1:}

Effects of the crude extracts of HB on SGOT, SGPT, creatinine and glucose levels in mice

\begin{tabular}{|l|l|l|l|l|}
\hline Group & SGOT (U/L) ${ }^{(\mathrm{y})}$ & SGPT $(\mathrm{U} / \mathrm{L})^{(\mathrm{y})}$ & ${\text { Glucose }(\mathrm{mg} / \mathrm{dL})^{(\mathrm{y})}}$ & $\begin{array}{l}\text { Creatinine (mg/dL) } \\
(\mathrm{y})\end{array}$ \\
\hline $\begin{array}{l}\text { Control } \\
\text { N/saline) }\end{array}$ & $121.40 \pm 19.93$ & $41.00 \pm 6.47$ & $138.84 \pm 8.08$ & $4.16 \pm 0.83$ \\
\hline $\begin{array}{l}\text { Aqueous } \\
\text { Extract }\end{array}$ & $115.20 \pm 6.90$ & $47.00 \pm 5.23$ & $143.66 \pm 7.58$ & $4.40 \pm 0.78$ \\
\hline $\begin{array}{l}\text { Aqueous +ethanol } \\
\text { Extract }\end{array}$ & $112.00 \pm 9.32$ & $45.40 \pm 9.77$ & $140.22 \pm 7.94$ & $3.44 \pm 0.78$ \\
\hline Ethanol Extract & $126.20 \pm 29.17$ & $45.80 \pm 29.00$ & $147.22 \pm 8.08$ & $5.26 \pm 1.28$ \\
\hline
\end{tabular}

${ }^{\left({ }^{(g)}\right.}$ Values are expressed as mean \pm S.E.M of 8 mice. ${ }^{*} P<0.05$ compared with control (Student's t-test). 
Table 2:

Effects of the AEHB, AQ/EEHB and EEHB on other basic haematological parameters

\begin{tabular}{|c|c|c|c|c|c|c|c|c|}
\hline Grp & $\begin{array}{l}{ }^{(y)} \mathbf{R B C} \\
\mathrm{M} / \mathbf{m m}^{3}\end{array}$ & $\begin{array}{l}\text { TWBC } \\
\mathbf{m} / \mathbf{m m}^{3(y)}\end{array}$ & $\begin{array}{l}\underset{\%^{(y)}}{\operatorname{Lymp}} \\
\end{array}$ & $\begin{array}{l}\text { Mono } \\
\%^{(y)}\end{array}$ & $\begin{array}{l}\text { Gran } \\
\%^{(y)}\end{array}$ & $\begin{array}{l}\text { Throm } \\
\text { m/mm }\end{array}$ & $\begin{array}{c}{ }^{(\mathrm{y})} \mathbf{H c t} \\
\%^{(\mathrm{y})}\end{array}$ & $\begin{array}{l}{ }^{(y)} \mathbf{H b} \\
\text { g/dL }\end{array}$ \\
\hline NSS & $\begin{array}{l}6.06 \\
0.45\end{array}$ & $\begin{array}{ll}20.42 & \pm \\
3.69 & \end{array}$ & $\begin{array}{ll}75.54 \quad \pm \\
1.92\end{array}$ & $\begin{array}{l}13.52 \\
0.45\end{array}$ & $\begin{array}{l}10.94 \\
1.43\end{array}$ & $\begin{array}{l}374.00 \pm \\
73.17\end{array}$ & $\begin{array}{l}30.28 \\
0.75\end{array}$ & $\begin{array}{ll}10.88 & \pm \\
0.24 & \end{array}$ \\
\hline AEHB & $\begin{array}{l}6.33 \\
0.29\end{array}$ & $\begin{array}{l}19.7 \\
\pm 2.20\end{array}$ & $\begin{array}{ll}68.86 \quad \pm \\
5.70\end{array}$ & $\begin{array}{l}18.40 \\
2.74\end{array}$ & $\begin{array}{l}12.74 \\
3.05\end{array}$ & $\begin{array}{l}* 530.00 \pm \\
43.60\end{array}$ & $\begin{array}{l}31.64 \\
1.13\end{array}$ & $\begin{array}{l}11.34 \\
0.42\end{array}$ \\
\hline AQ/EEHB & $\begin{array}{l}6.28 \\
0.34\end{array}$ & $\begin{array}{l}* 15.70 \quad \pm \\
1.40\end{array}$ & $\begin{array}{l}* 65.28 \quad \pm \\
3.47\end{array}$ & $\begin{array}{l}20.56 \\
2.07\end{array}$ & $\begin{array}{l}14.16 \\
1.43\end{array}$ & $\begin{array}{l}* 566.20 \pm \\
80.12\end{array}$ & \begin{tabular}{|l|}
30.92 \\
1.71 \\
\end{tabular} & $\begin{array}{l}11.50 \\
0.75\end{array}$ \\
\hline $\mathbf{E}$ & $\begin{array}{l}6.42 \\
0.15\end{array}$ & $\begin{array}{ll}21.64 & \pm \\
3.65 & \end{array}$ & $\begin{array}{ll}72.80 & \pm \\
2.33 & \\
\end{array}$ & $\begin{array}{l}14.30 \\
0.93\end{array}$ & $\begin{array}{l}12.74 \\
1.89\end{array}$ & $\begin{array}{l}* 559.20 \pm \\
57.40\end{array}$ & $\begin{array}{l}32.32 \\
1.02\end{array}$ & $\begin{array}{l}11.54 \\
0.28\end{array}$ \\
\hline
\end{tabular}

${ }^{(y)}$ Values are expressed as mean \pm S.E.M of 8 mice. ${ }^{*} \mathrm{P}<0.05$ compared with control (Student’s $t$-test).

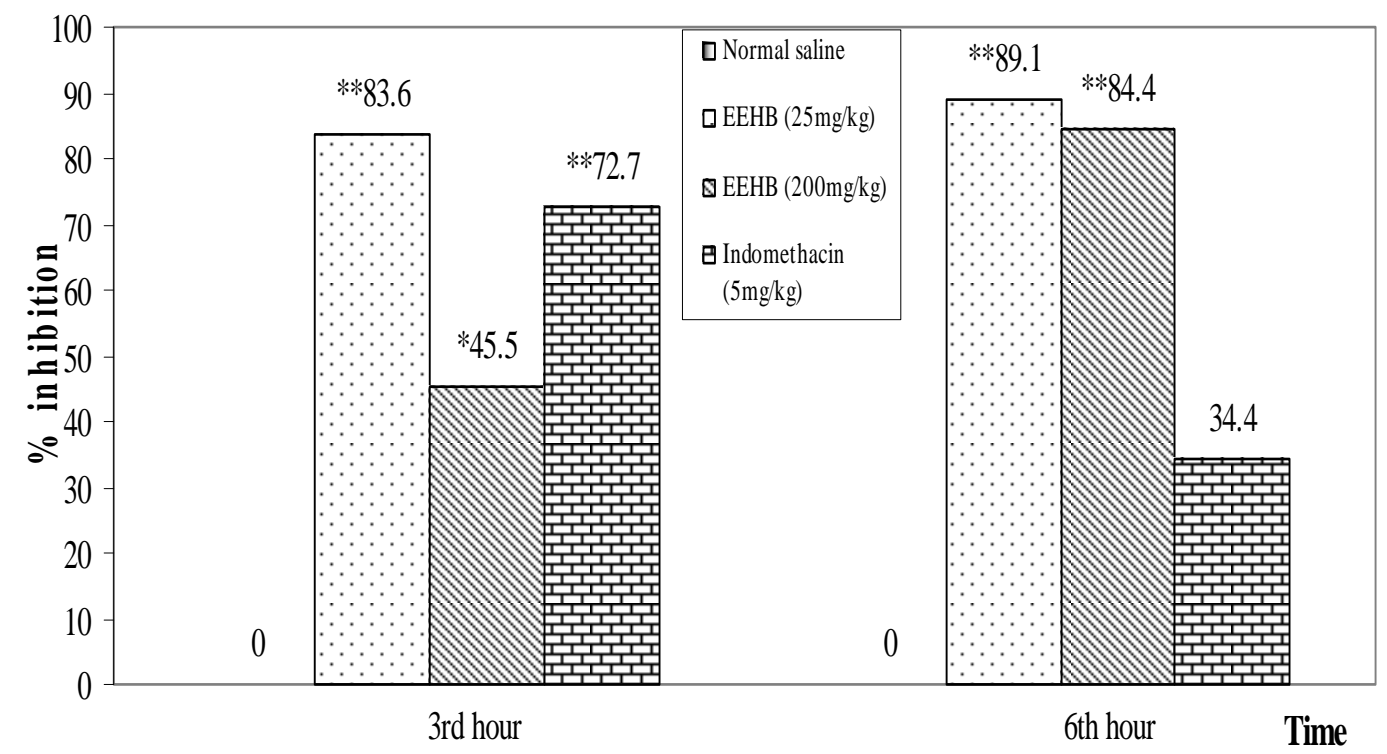

Figure 1: Effects of EEHB on carrageenan-induced paw oedema in rats (in-vivo). Values are expressed as mean \pm S.E.M of 8 rats. $* \mathrm{P}<0.05,{ }^{* *} \mathrm{P}<0.001$ compared with control (Student's $t$-test).

Evaluation of the hematological parameters in mice

Table 2 shows the results of basic hematological parameters measured in mice treated with crude extracts of $H B$ leaf. Treatment with AQ/EEHB significantly reduced the TWBC and lymphocyte counts. All the extracts significantly increased the thrombocyte counts $(\mathrm{P}<0.05)$.

Anti-microbial screening of the crude extracts of HB: No extracts were found active against any of the bacteria strains used.

\section{Carrageenan-induced paw oedema test}

Figure 1 shows the anti-inflammatory potency of EEHB on carrageenan-induced paw oedema. $25 \mathrm{mg} / \mathrm{kg}$ of EEHB shows the highest antiinflammatory activity at the 3rd and 6th hours compared with the other groups.

\section{Formalin-induced paw licking test}

Figure 2 shows the effects of EEHB leaf on formalin-induced paw licking in the early and late 
phases. 25mg/kg of EEHB has a higher analgesic

activity than the $200 \mathrm{mg} / \mathrm{kg}$.

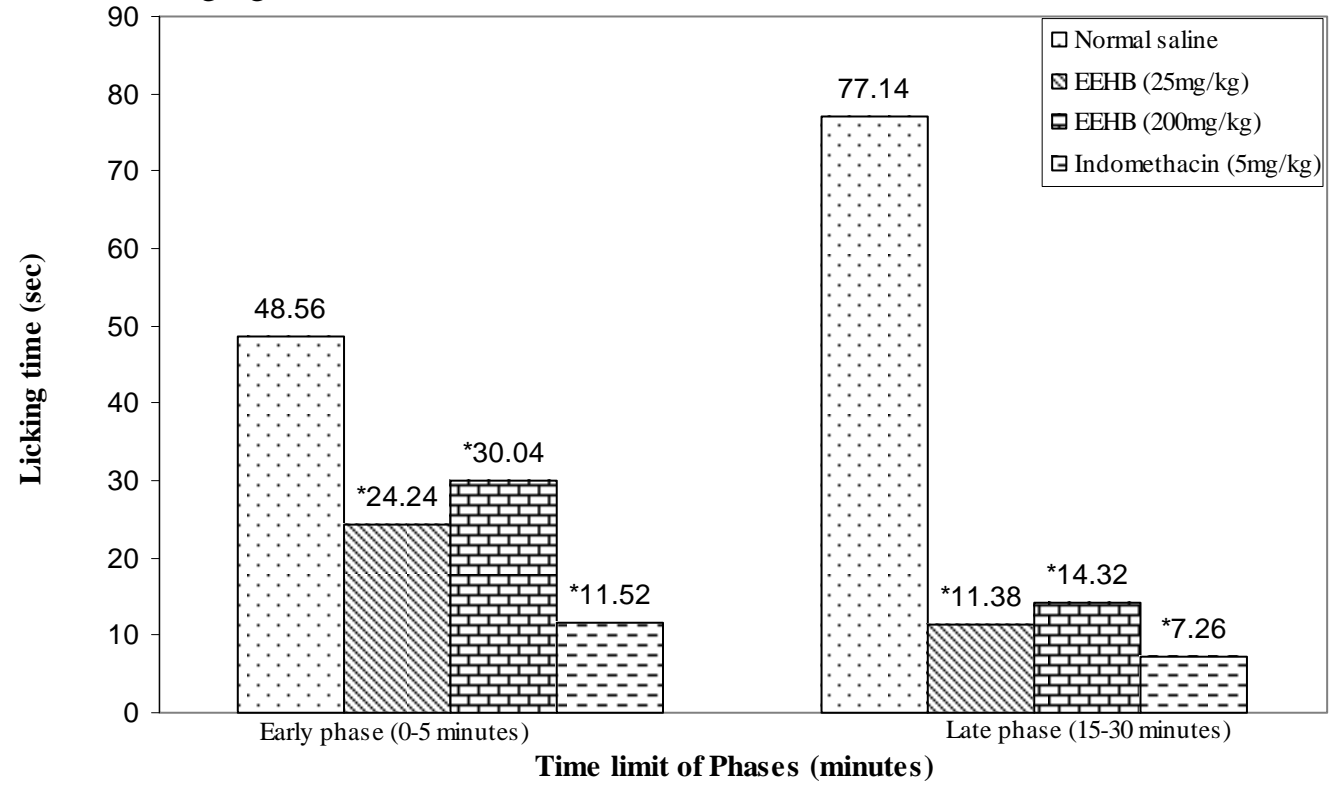

Figure 2:

Effects of EEHB on formalin-induced paw licking in mice. Values are expressed as mean \pm S.E.M of 8 rats. $* \mathrm{P}<0.05$ compared with control (Student's $t$-test).

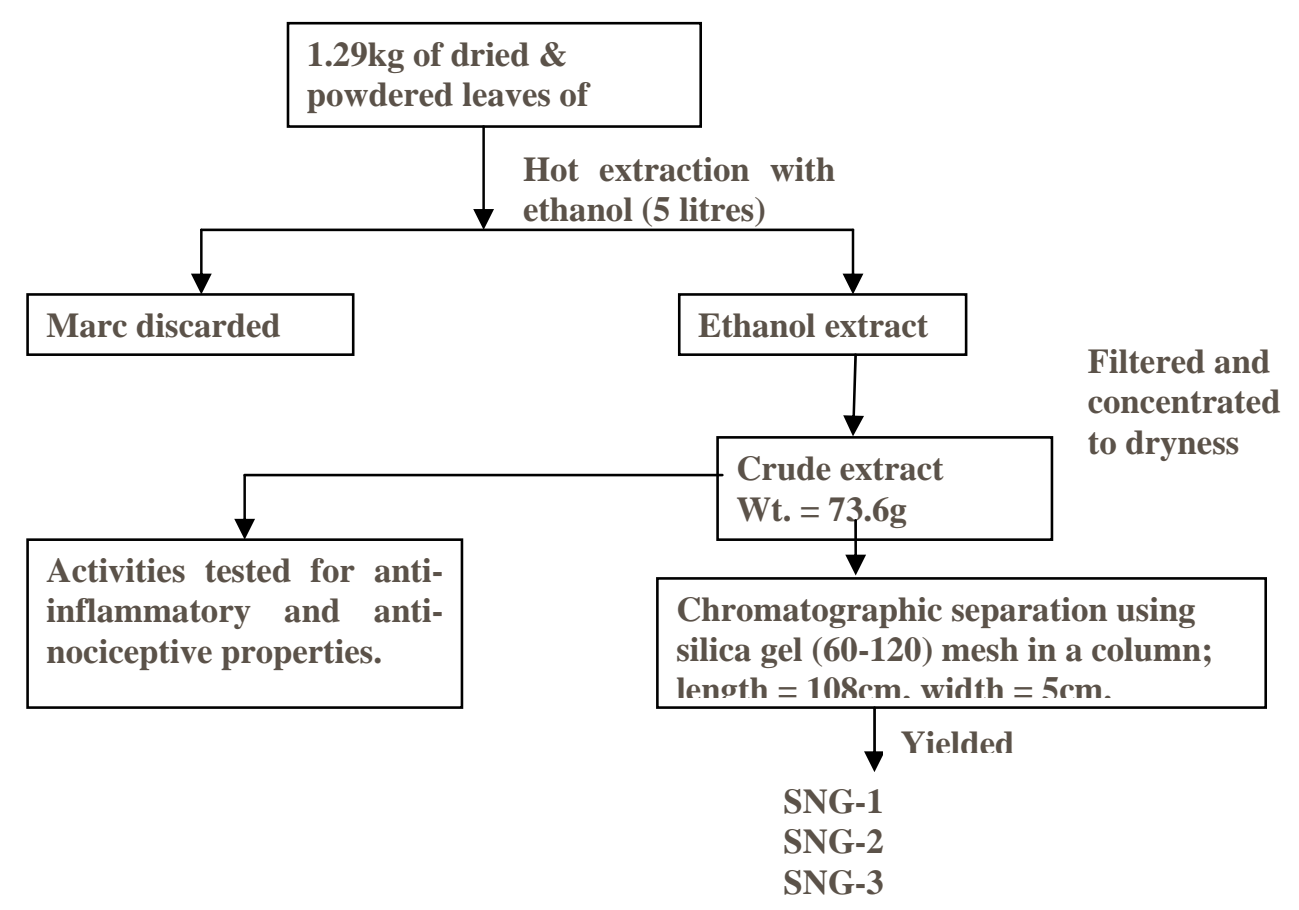

Figure 3: Extraction and isolation of the chemical constituents of EEHB leaf. 


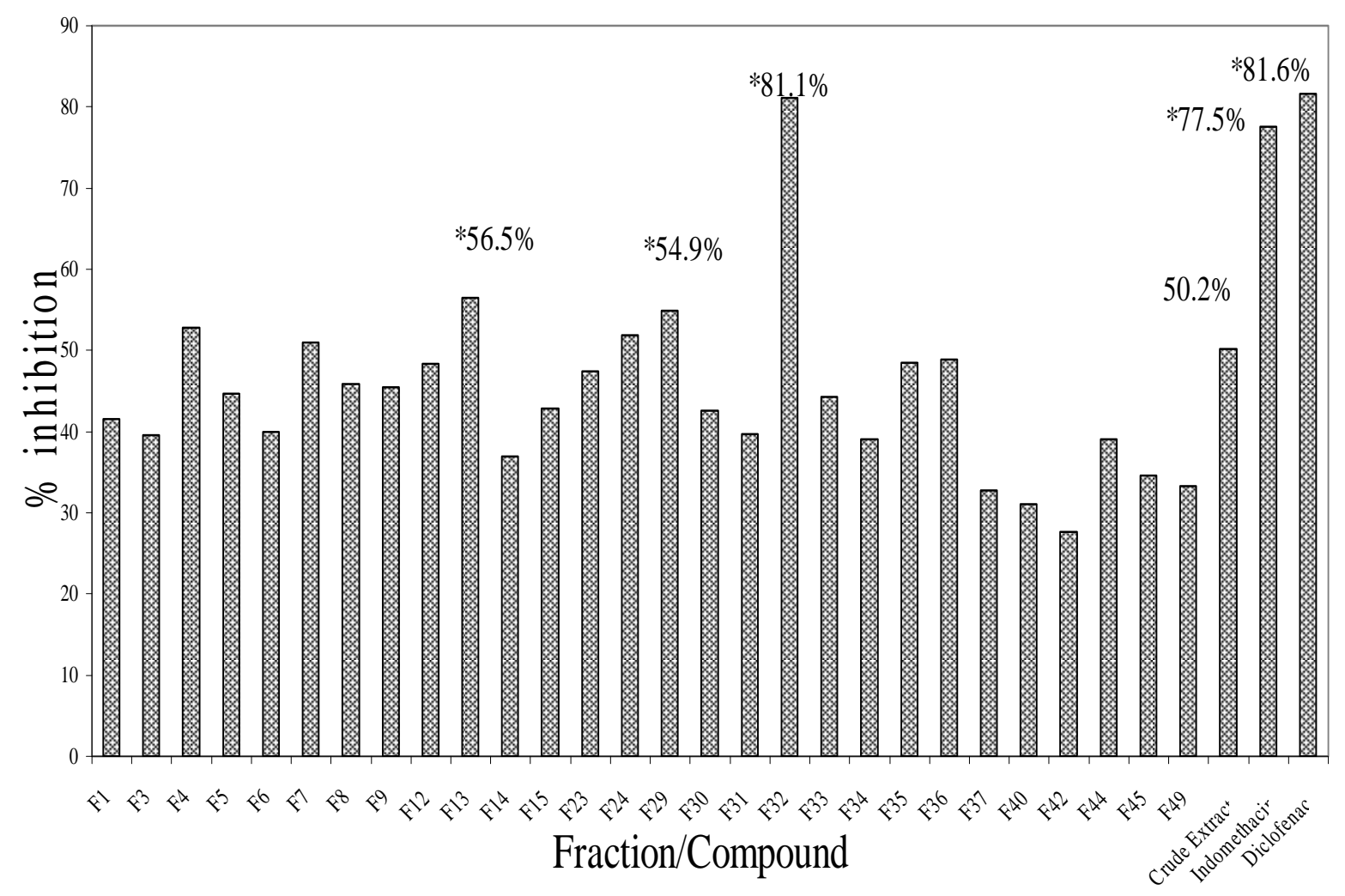

Figure 4:

Screening of various fractions of EEHB from column chromatography for COX-2 inhibiting activity (in-vitro). $* \mathrm{P}<0.05$ (significant).

Column chromatographic separation of EEHB

271 samples of the extract were collected and were grouped into 55 fractions, which were later subgrouped into 11 sub-fractions based on their relative flow (Rf).

In-vitro screening of EEHB fractions for COX2 inhibiting activity

The fractions F29 (sample 72), F32 (sample 8184) and F13 (sample 194-198) produced inhibition above 55\% using COX-2 inhibiting assay (in-vitro screening) as shown in figure 4.

Anti-inflammatory screening of EEHB fractions (In-vivo)

Carrageenan-induced paw oedema test

The effects of F13, F29 and F32 of EEHB on carrageenan-induced paw oedema in rats are shown in figure 5 . At the 1st, 2nd and 3rd hours (post treatment), F29 and F32 of EEHB showed the highest anti-inflammatory activities respectively $(\mathrm{P}<0.05)$.

\section{In-vivo anti-nociceptive screening of EEHB} fractions

Acetic acid-induced writhing test: The antinociceptive properties of F13, F29, and F32 of EEHB on mice using the acetic acid writhing model are shown in Table 3. F32 afforded the highest inhibition of writhing in mice amongst the three fractions.

\section{Formalin-induced paw licking test}

Figure 7 shows the results of the anti-nociceptive properties of F13, F29 and F32 of EEHB on formalin-induced paw licking in albino rats. In both phases, the formalin-induced paw licking response values in the extract treated rats were significantly reduced with F29 showing the highest analgesic activity compared with F13 and 
F32 of EEHB.

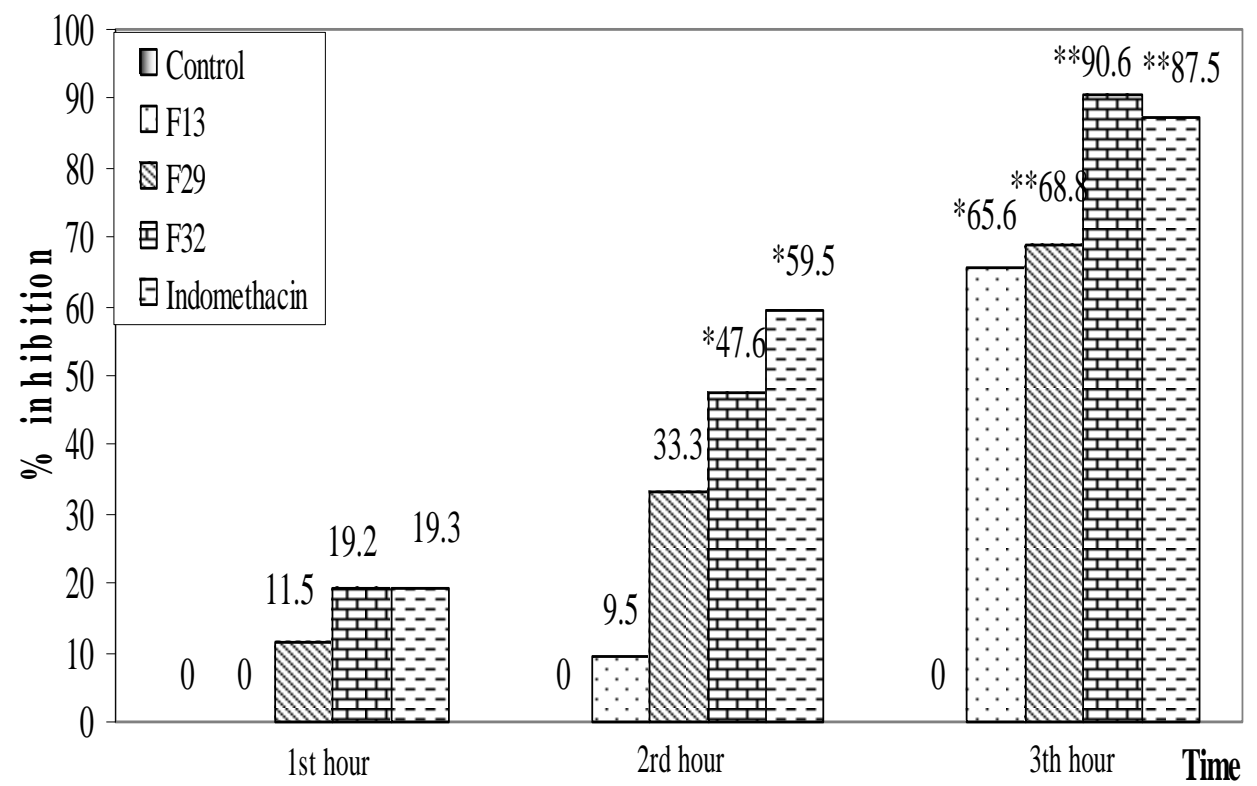

Figure 5:

Anti-inflammatory properties of the EEHB fractions on carrageenan-induced paw edema in rats. Values are expressed as mean \pm S.E.M of 8 rats. ${ }^{*} \mathrm{P}<0.05,{ }^{* *} \mathrm{P}<0.001$ compared with control (Student's $t$-test).

Table 3:

Anti-nociceptive properties of EEHB on acetic acid-induced writhing in mice

\begin{tabular}{|l|l|l|l|}
\hline Group & $\begin{array}{l}\text { Dose } \\
(\mathbf{m g} / \mathbf{k g})\end{array}$ & $\begin{array}{l}\text { Mean number of } \\
\text { writhing (per 10 } \\
\text { min.) }\end{array}$ & $\begin{array}{l}\text { \%) } \\
\text { Inhibition }\end{array}$ \\
\hline NS & $10 \mathrm{ml} / \mathrm{kg}$ & $52.6 \pm 3.70$ & 0 \\
\hline F13 & 25 & $27.2 \pm 5.25$ & $* 48.3$ \\
\hline F29 & 25 & $23.2 \pm 3.63$ & $* 55.9$ \\
\hline F32 & 25 & $20.4 \pm 1.33$ & $* 61.2$ \\
\hline IND & 5 & $8.8 \pm 3.51$ & $* * 83.3$ \\
\hline
\end{tabular}

NS = Normal saline $;$ IND = Indomethacin

${ }^{(y)}$ Values are expressed as mean \pm S.E.M of 8 mice. ${ }^{* P}$ $<0.05$, ${ }^{* *} P<0.001$ compared with control (Student's t-test).

Compounds separation from EEHB fractions using preparative TLC and column chromatography

The use of preparative TLC separated SNG-1 from
F29 on glass plates pre-coated with silica gel $60 \mathrm{G}_{254}$ (E-Merck) with ethyl acetate: hexane (1:9) as shown on table 4 . The F32 of $550 \mathrm{mg}$ was rechromatographed over $50 \mathrm{~g}$ silica gel in a glass column, eluted with hexane and then varying proportion of hexane and chloroform. SNG-2 and SNG-3 were separated on preparative TLC glass plates pre-coated with silica gel $60 \mathrm{~F}_{254}$ from subfractions (15-18) and (123-137) respectively as summarized in table 5. These compounds were given for spectral analysis (1H-NMR, 13C-NMR, FAB MS and IR).

SNG 1 was suggested to be an estearic compound. It contains long chain aliphatic compound, which makes it aromatic in nature. SNG 2 elucidation suggests beta-sitosterol.

\section{DISCUSSION}

The effects of the hydro-ethanol extract of Hedranthera barteri (HB) leaf and their fractions were studied in this experiment using some pharmacological and toxicity studies. The changes in weights induced in mice by AEHB, AQ/EEHB 
and EEHB extracts revealed no significant difference.

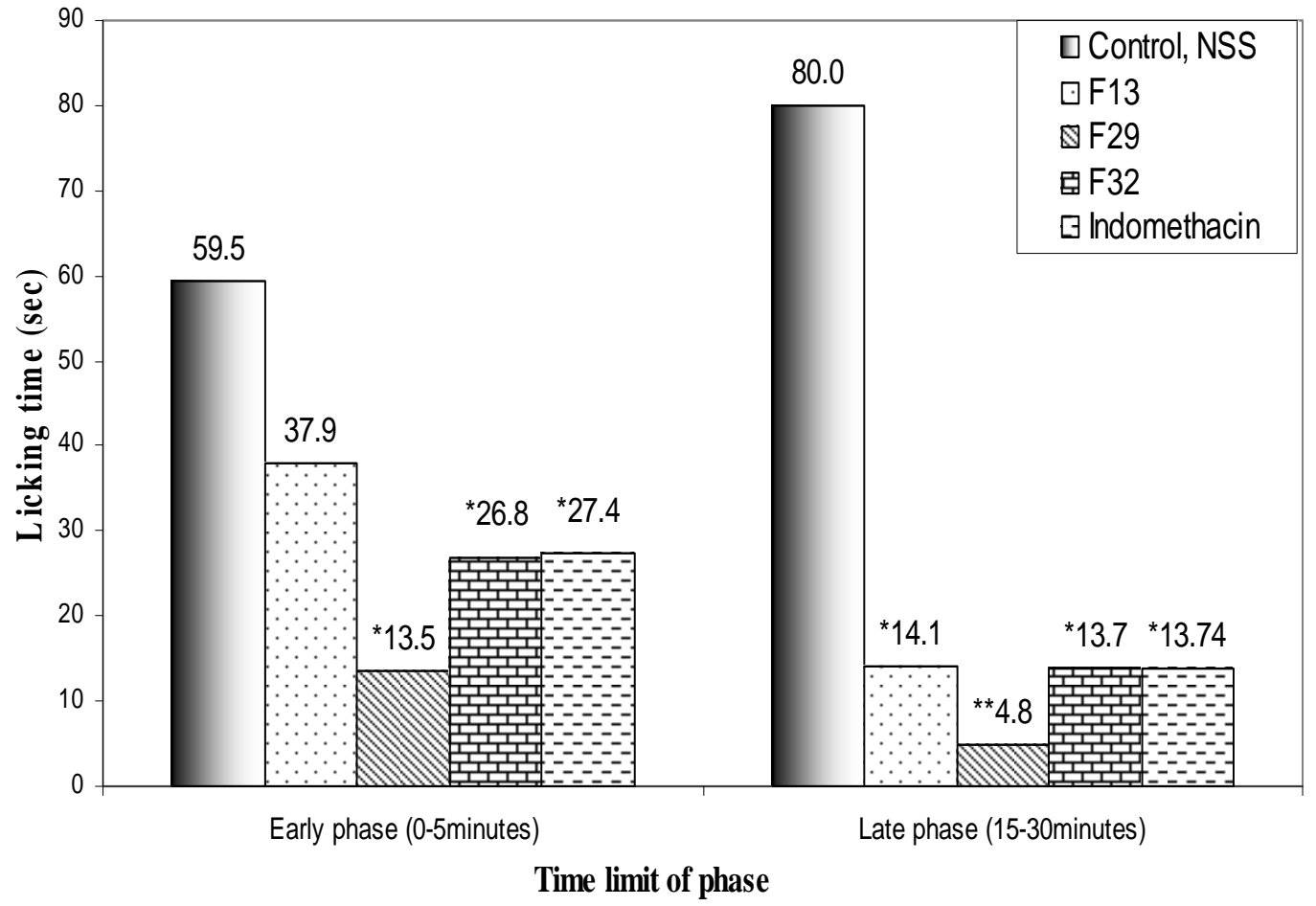

\section{Figure 6:}

Anti-nociceptive properties of EEHB on formalin-induced paw licking in rats. Values are expressed as mean \pm S.E.M of 8 rats. ${ }^{*} \mathrm{P}<0.05,{ }^{* *} \mathrm{P}<0.001$ compared with control (Student's t-test).

Table 4:

Preparative TLC of F29 of EEHB

\begin{tabular}{|c|c|c|c|c|c|}
\hline S/No. & Code & Weight (mg) & $\begin{array}{c}\text { Preparative TLC solvent } \\
\text { system }\end{array}$ & R.f. & Fraction \\
\hline 1. & SNG-1 & $20 \mathrm{mg}$ & Ethyl acetate: hexane (1:9) & 0.69 & F29 \\
\hline
\end{tabular}

Table 5:

Preparative TLC of sub-fractions from F32 of EEHB

\begin{tabular}{|c|c|c|c|c|c|}
\hline S. No. & Code & Wt. (mg.) & $\begin{array}{c}\text { Preparative TLC solvent } \\
\text { system }\end{array}$ & R.f. & Sub-fractions \\
\hline 1. & SNG-2 & 19.0 & $\begin{array}{c}\text { Ethyl acetate: hexane } \\
(10: 90)\end{array}$ & 0.78 & $15-18$ \\
\hline
\end{tabular}




\begin{tabular}{l|c|c|c|c|c|}
\hline \hline \multicolumn{6}{|c|}{} \\
\hline 2. & SNG-3 & 21.0 & $\begin{array}{c}\text { Chloroform: methanol } \\
(99: 1)\end{array}$ & 0.77 & $123-156$ \\
\hline
\end{tabular}

The insignificant effects of AEHB, AQ/EEHB and EEHB extracts on SGOT, SGPT, creatinine and glucose levels in table 1 after 4 weeks shows that the extracts may not be toxic to major enzymes involved in basic metabolic activities in the tissues, liver and kidneys.

In the acute toxicity studies, hydro-ethanol extracts of HB $(2 \mathrm{~g} / \mathrm{kg})$ given per os every 24hours for 4 weeks did not produce any death in the animals. No significant sign of toxicity was observed during the experiment. Hence, $200 \mathrm{mg} / \mathrm{kg}$ was considered to be effective for the crude extract (Onasanwo and Elegbe, 2006).

The hematological data (table 2) showed no toxic implication. The thrombocyte counts in all the extract-treated groups were significantly increased $(\mathrm{P}<0.05)$ compared with the control group. Generally, the values of RBC and WBC were slightly increased and/or decreased. The observed effects of the plant extracts on different elements of the blood seem to suggest that the plant has little haemopoietic functions. Although there are no previous studies to support this fact but the phytochemistry of the extract reveals the presence of alkaloids and steroidal saponins (Onasanwo and Elegbe, 2006) that may enhance blood production (Tyler et al, 1981) and treatment of anaemia, enhancing blood production (Trease and Evans, 1999) respectively. The mechanisms involved are not known but more haematological analyses are still on to elucidate the possible mechanism of its action.

Also, hydro-ethanol extract of Hedranthera barteri showed analgesic and anti-inflammatory potencies, which confirms the anti-nociceptive and anti-inflammatory properties of aqueous, methanol and chloroform extracts of HB leaf (Onasanwo and Elegbe, 2006). The lower dose $(25 \mathrm{mg} / \mathrm{kg})$ showed better significance $(\mathrm{P}<0.05)$ than the $200 \mathrm{mg} / \mathrm{kg}$ dose, which is comparable with indomethacin in carrageenan-induced paw oedema and formalin-induced paw licking in rats and mice respectively $(\mathrm{P}<0.05)$.

In the extraction and isolation of the chemical constituents in the EEHB through Column
Chromatography, 271 samples of the extract were collected and were grouped into 55 fractions which were later classified, based on the eluents, into 11 sub-fractions. Ethanol extract of HB was used for the column chromatography since EEHB is expected to contain virtually the active compounds of the leaf (Pieme et al, 2006). The screening for COX-2 inhibitory activity through Enzyme Immuno-assay (EIA) using the in-vitro Cayman COX (ovine) inhibitor-screening assay was used because it directly measures $\mathrm{PGF}_{2}$ produced by $\mathrm{SnCl}_{2}$ reduction of COX-derived $\mathrm{PGFH}_{2}$. The prostanoid product is quantified via enzyme immunoassay (EIA) using a broadly specific antibody that binds to all the major prostaglandin compounds. The identification of high percentage inhibition by F13, F29 and F32 amongst many fractions, when compared with the standard drugs, indomethacin (short half-life drug) and diclofenac (long half-life drug) in figure 5 shows that the secondary metabolites/active compounds responsible for the anti-nociceptive and anti-inflammatory properties may be concentrated in these fractions.

In-vivo testing of the sub-fractions showed that the anti-inflammatory property of F32 was highly significant compared with F13 and F29, which also showed higher percentage inhibition than indomethacin. In acetic acid-induced writhing, percentage inhibition as shown in table 3 is higher in F32 (61.2\%) followed by F29 (55.9\%) and then F13 (48.3\%) compared with the control. This depicts that F32 may contain the most active metabolite(s) responsible for the anti-nociceptive properties of HB which is relatively higher than F29 and then F13. In formalin-induced paw licking in mice, F29 caused the least number of licks both at the early and late phases. Hence, secondary metabolite(s) that are active at the peripheral level in formalin-induced paw licking may be present in F29 which is relatively higher than in F13 and F32, even indomethacin.

Fractions F13, F29 and F32 were further chromatographed which separated SNG 1, SNG 2 and SNG 3 from F29 and F32. The structural 
elucidation of the compounds SNG 1, SNG 2 and SNG 3 were suggested from spectral analysis (1HNMR, 13CNMR, IR and FABMS). SNG 1 was suggested to be an estearic compound. It contains long chain aliphatic compound, which makes it aromatic in nature. SNG 2 elucidation suggests beta-sitosterol, which is known to be a potent anti-inflammatory and pain-reducing compound. Systematic separation of the fatty/oily compounds is on to validate this finding. Therefore this SNG 2 may be responsible for the anti-nociceptive and anti-inflammatory properties of F32. SNG 3 spectral is very close in identification to that of SNG 2 but there is still need for further analysis, which was restricted due to infinitesimally small sample left after spectral analysis. It is therefore suggested that antinociceptive compound(s) seems to be present in higher concentration in F29 than F32 while the anti-inflammatory compound(s) seems to be present in higher concentration in F32 than F29. Further work is on to establish the findings stated above.

\section{Acknowledgements}

This work was supported by TWAS (Italy) and CSIR (India) under TWAS/CSIR Postgraduate Fellowship 2004.

\section{References}

Ainslie J.R. (1937): A List of plant used in Native Medicine in Nigeria. Imperial forestry Institute, Oxford, paper 7 (Mimeographed), pg 30.

Aydin S., Beis R., Öztürk Y., Hüsnü H. and Baser C. (1998): Nepetalactone: a new opIoid analgesic from Nepeta cesearea Boiss. J. Pharm Pharmacol 50: 813 817.

Bauer A.W., Kriby W.M.M., Sherries J.C. and Turck M. (1996): Antibiotic susceptibility testing by Standard single Disc Methods. Amer. J. Clin. Path. 45: 493 - 496.

Botham P.A. (2004): Acute System Toxicity-prospects for tiered testing strategies. Toxicity in vitro, 18: 227230.

Chukwujekwu JC, Staden J.V and Smith P (2005): Antibacterial, anti-inflammatory and antimalarial activities of some Nigerian medicinal plants. South Afr. J. Bot. 71 (3 \& 4): 316 - 325.
Dalziel J. M. (1937): The useful plants of West Tropical Africa, Crown Agents for the Colonies, London. Punch 48, K.

El Sayah M., Cechinel Filho V., Pinheiro T.C., Yunes R.A. and Calixto J.B. (1999): In vitro effect of the extract and the 1, 7-dihydroxy-2, 3-dimethoxy xanthone from Polygala cyparissias on the contraction induced by inflammatory mediators and ovalbumin in normal and activity sensitized trachea from guinea pig. Inflamm. Res. 48: 218-223.

Hunskaar S. And Hole K. (1997): The formalin test in mice: dissociation between inflammatory and noninflammatory and pain. Pain 30: 103-114.

Koster R., Anderson M. and De Beer E.J. (1959): Acetic acid analgesic screening. Federation Proceedings 18, 412.

Murray C. W., Porreca F. and Cowan A. (1988): Pharmacology methods, 20: 175-186.

Onasanwo S.A. and Elegbe R.A. (2006): Antinociceptive and anti-inflammatory properties of the leaf extracts of Hedranthera barteri in rats and mice.

African Journal of Biomedical Research, Vol. 9 (2006); $109-117$.

Piemel C.A., Penlap V.N., Nkegoum B., Taziebou1 C. L., Tekwu E.M., Etoa1 F.X., Ngongang J. (2006). Evaluation of acute and subacute toxicities of aqueous ethanolic extract of leaves of Senna alata (L.) Roxb (Ceasalpiniaceae). African Journal of Biotechnology Vol. 5 (3) pp. 283-289.

Pinheiro T.R., Cechinel-Filho V. and Santos A.R.S. (1998): Three xanthones from Polygala cyparissias. Phytochemistry 48: 725-728.

Siegmund E., Cadmus R. and Lu G. (1957): A method for evaluating narcotic and non-narcotic analgesics. Proceedings of the society of Experimental Biology and Medicine. 95: 729-731.

Trease G. E. and Evans W. C. (1999): A textbook of Pharmacognosy, 14th Edition, London . W.B. Saunder Company Ltd, pp. 58-302.

Tyler V.E., Brady L.R. and Roberts J.F. (1981): Pharmacognosy 8th edition, Philadelphia: Lea and Ferbiger, pp. 58, 78, 171,198.

Uma-Devi P., Ganasoundari A., Rao S.B. and Sriivasan K.K. (1999): In vivo radioprotection by Ocimum Flavonoids: survival of mice. Radiation Research. 151 (1): 74-78.

Winter C. A., Risley E. A. and Nuss C. W. (1962): Carrageenan-induced oedema in the hind paw of the rat as an assay for anti-inflammatory drugs. Proceedings of the Society for Experimental Biology and Medicine, Vol. 111: 544-547. 
African Journal of Biomedical Research, Vol. 11 (2008); 311 - 321

ISSN 1119 - 5096 @ Ibadan Biomedical Communications Group



Abstracted by:

African Index Medicus (WHO), CAB Abstracts, Index Copernicus, Global Health Abstracts, Asian Science Index, Index Veterinarius, Bioline International , African Journals online 